\title{
Combating 2019-nCoV Amidst the Pandemic Scare
}

\author{
Khawaja Husnain Haider ${ }^{1}$, Qurratulain Hyder ${ }^{2}$ \\ ${ }^{1}$ Department of Basic Sciences, Sulaiman AlRajhi University, Al Bukairiyah, Kingdom of Saudi Arabia \\ ${ }^{2}$ Gastroenterology Clinics, Pakistan Institute of Medical Sciences (PIMS), G-8/3, Islamabad, Pakistan \\ Email:khhaider@gmail.com, kh.haider@sr.edu.sa, qhyderA2194@hotmail.com.uk
}

How to cite this paper: Haider, K.H. and Hyder, Q. (2020) Combating 2019-nCoV Amidst the Pandemic Scare. Open Journal of Regenerative Medicine, 9, 15-19. https://doi.org/10.4236/ojrm.2020.92003

Received: March 26, 2020

Accepted: April 17, 2020

Published: April 20, 2020

Copyright $\odot 2020$ by author(s) and Scientific Research Publishing Inc. This work is licensed under the Creative Commons Attribution International License (CC BY 4.0).

http://creativecommons.org/licenses/by/4.0/

\begin{abstract}
2019-nCoV is the third consecutive coronavirus spread during the last 2 decades, but this time, unlike the previous two occasions, has achieved a pandemic proportion threatening widespread loss of human lives and a massive setback to the global economy. The situation warrants drastic measures in terms of preventing the spread of the virus and treating the virus-infected patients. The development of a new vaccine is a time-intensive option. Although efforts are underway to find possible pharmacological options, e.g., chloroquine, hydroxychloroquine, existing antiviral agents, etc., in the meanwhile we may work on the combinatorial interventional approach of combining drug therapy with passive immune therapy. It would be prudent to use a convalescent serum therapy approach with the serum from COVID-19 patients who have recovered from the infection.
\end{abstract}

\section{Keywords}

Coronavirus, COVID-19, Immunotherapy, Passive, Chloroquine

\section{Introduction}

At the time when I am writing this manuscript, more than 76,000 2019-nCoV infected patients have died, out of a total of more than 1,362,000 cases reported around the world in more than 190 countries, and the number is increasing relentlessly every hour of the day [1]. From amongst the remaining patients, 94\% (nearly a million patients) have mild condition while $5 \%$ of patients are seriously ill. These figures are alarming and warrant drastic measures to stop the situation from sliding down further to prevent any human catastrophe. Although concerted efforts involving the researchers in both academia and pharmaceutical industries are underway to restrain the spread of infection and find its treat- 
ment, there is little insight in terms of vaccination or pharmacological options for the treatment of 2019-nCoV infected patients [2]. Several anti-viral drugs with the diverse mechanism of action, attacking the virus by interfering with its attachment to the cells to its replication and exit from the infected cells, are currently being assessed for their efficacy against 2019-nCoV [3]. The latest breakthrough in the pharmacological management of 2019-nCoV infection has been reported with the use of chloroquine (CQ) and hydroxychloroquine (HCQ), which has given some hope amidst the existing COVID-19 scare [4]. CQ and HCQ are the semi-synthetic derivatives of quinine; cinchona bark-derived alkaloid with proven antimalarial activity although these anti-malarial drugs have nearly lost their clinical use due to the malarial parasite developing resistance [5]. Encouraged by the data from QC and HCQ against SARS-CoV [6] [7] and their successful use in Wuhan, China, a research group from Marseille, France has published the results of a non-randomized open-label single-arm study in confirmed cases of 2019-nCoV infected patients. The patients received $600 \mathrm{mg}$ daily dose of hydroxychloroquine (in three divided doses of $200 \mathrm{mg}$ each) with or without azithromycin in hospitalized patients [8]. The data showed $70 \%$ of the HCQ treated patients as virologically cured on day 6 as compared to $12.5 \%$ control patients from another center who declined to be treated with the study protocol. Additionally, treatment with azithromycin synergistically enhanced the effect of HCQ. Efforts are also underway to screen the existing armory of antivirals against 2019-nCoV. Wang et al., have reported that HCQ combined with nucleotide analog remdesivir was effective to inhibit 2019-nCoV in vitro [9]. Currently, 2 phase-III randomized open-label trials (NCT04292899; NCT04292730) sponsored by the National Institute of Health (NIH), are in the phase of enrolment to assess remdesivir in persons with COVID-19. Similarly, Europe is also starting clinical trials involving 3200 patients for the assessment of some anti-viral agents including remdesivir and CQ [10].

Incidentally, chloroquine has been included in the guidelines issued by the National Health Commission of the Peoples' Republic of China (NHCPRC) for the treatment of 2019-nCoV caused pneumonia. This short paper discusses the possible use of passive immunotherapy with chloroquine and its derivatives as a combinatorial therapeutic intervention for $2019-\mathrm{nCoV}$ infected patients.

\section{Coronaviruses}

Coronaviruses constitute a large family of enveloped, positive single-stranded RNA viruses, which are mostly found in the animals but some of them have potential infectivity in the humans with pathogenic consequences, mostly related to the upper respiratory tract. $2019-\mathrm{nCoV}$ is the third major spread of coronaviruses after Severe Acute Respiratory Syndrome (SARS)-CoV and Middle East Respiratory Syndrome (MERS)-CoV during the last 2 decades, inflicting heavy losses in terms of human life, as well as a serious global economic setback [10] [11]. Whereas both SARS-CoV and MERS-CoV were of zoonotic origin, the ori- 
gin of 2019-nCoV is still debatable [12].

\section{Convalescent Serum Therapy for Passive Immunization: A Viable Option for COVID-19 Patients}

Passive immunization strategy is not new to the treatment of both bacterial and viral infections as it started in the $20^{\text {th }}$ century with the use of animal sera to passively support the compromised immune system of patients using specific antibodies from an exogenous source. Subsequently, with the advancements in the purification and fractionation technology, the use of animal sera was replaced with the human-derived sera [13]. However, since the inception of hybridoma technology by Kohler and Milstein in the early 80 's and the subsequent advent and progress made therein, the use of monoclonal antibodies (MAbs) and their derivative fractions have substituted the use of animal and human sera for many diseases. MAbs provide a renewable source of preparations with high specificity and standardized potency. Currently, more than 80 FDA approved MAb preparations are available in the market for patients with pathological conditions encompassing from cancer to cardiovascular pathologies [14]. Recent advancement in the passive immunization approach is the use of the chimeric antigen receptor T-cells (CAR T-cells) approach [15].

The passive immunization approach may be given serious consideration as a viable option to passively immunize the $2019-\mathrm{nCoV}$ infected patients by convalescent serum therapy wherein serum obtained from the patients who have survived and recovered from the infection can be used [16].

Passive immunization offers the patient a short-lived protection, which may vary in duration from a few weeks to a few months. The use of human serum has been extensively studied in culturing of the donor cells for in vitro expansion and has been preferred over animal serum to enhance their immunological acceptance by the recipient post-engraftment. Similarly, autologous patient serum is regularly used as a medium to suspend cells for transplantation in cell-based therapy procedures. The use of convalescent patient serum is surely a superior choice in terms of curtailed immunogenicity as compared to blood plasma preparations due to their depleted protein contents. The situation warrants optimization of protocols in accordance with the existing Good Manufacturing Practices to initiate a drive to collect $250-300 \mathrm{ml}$ blood from nearly 293,000 convalescent patients to secure nearly $4.5 \times 10^{7} \mathrm{ml}$ of their precious serum that may be enough to treat the patients with an active infection under the prevailing circumstances. Moreover, combining convalescent serum therapy to enhance the compromised immune system of the patients with the pharmacological intervention using CQ, HCQ, and anti-viral agents etc., the combinatorial approach may allow the researchers to treat $2019-\mathrm{nCoV}$ infected patients. While pharmacological intervention will provide anti-viral effects, serum therapy will be supportive for the depleted immune system of the patient. The use of combinatorial approach will allow ample time to researchers to develop an anti-2019-nCoV 
vaccine, assess the effectiveness of the existing anti-viral drugs, and search for effective novel molecules against the novel coronavirus without the further loss of human lives.

\section{Conflicts of Interest}

The authors declare no conflicts of interest regarding the publication of this paper.

\section{References}

[1] https://www.worldometers.info/coronavirus

[2] Lu, H. (2020) Drug Treatment Options for the 2019-New Coronavirus (2019-nCoV). BioScience Trends, 14, 69-71. https://doi.org/10.5582/bst.2020.01020

[3] Dong, L., Hu, S. and Gao, J. (2020) Discovering Drugs to Treat Coronavirus Disease 2019 (COVID-19). Drug Discoveries \& Therapeutics, 14, 58-60. https://doi.org/10.5582/ddt.2020.01012

[4] Gao, J., Tian, Z. and Yang, X. (2020) Breakthrough: Chloroquine Phosphate Has Shown Apparent Efficacy in Treatment of COVID-19 Associated Pneumonia in Clinical Studies. BioScience Trends, 14, 72-73. https://doi.org/10.5582/bst.2020.01047

[5] Warhurst, D.C., Steele, J.C., Adagu, I.S., Craig, J.C. and Cullander, C. (2003) Hydroxychloroquine Is Much Less Active than Chloroquine against Chloroquine-Resistant Plasmodium falciparum, in Agreement with Its Physicochemical Properties. Journal of Antimicrobial Chemotherapy, 52, 188-193. https://doi.org/10.1093/jac/dkg319

[6] Keyaerts, E., Vijgen, L., Maes, P., Neyts, J. and Van Ranst, M. (2004) In Vitro Inhibition of Severe Acute Respiratory Syndrome Coronavirus by Chloroquine. Biochemical and Biophysical Research Communications, 323, 264-268. https://doi.org/10.1016/j.bbrc.2004.08.085

[7] Liu, J., Cao, R., Xu, M., Wang, X., Zhang, H., Hu, H., et al. (2020) Hydroxychloroquine, a Less Toxic Derivative of Chloroquine, Is Effective in Inhibiting SARS-CoV-2 Infection in Vitro. Cell Discovery, 6, 16. https://doi.org/10.1038/s41421-020-0156-0

[8] Gautretab, P., Lagierac, J.-C., Parolaab, P., Hoang, V.-T., Meddeba, L., Mailhea, M., et al. (2020) Hydroxychloroquine and Azithromycin as a Treatment of COVID-19: Results of an Open-Label Non-Randomized Clinical Trial. International Journal of Antimicrobial Agents.

[9] Wang, M., Cao, R., Zhang, L., Yang, X., Liu, J., Xu, M., et al. (2020) Remdesivir and Chloroquine Effectively Inhibit the Recently Emerged Novel Coronavirus (2019-nCoV) in Vitro. Cell Research, 30, 269-271. https://doi.org/10.1038/s41422-020-0282-0

[10] https://presse.inserm.fr/lancement-dun-essai-clinique-europeen-contre-le-covid-19 138737

[11] Andersen, K.G., Rambaut, A., Lipkin, W.I., Holmes, E.C. and Garry, R.F. (2020) The Proximal Origin of SARS-CoV-2. Nature Medicine. https://doi.org/10.1038/s41591-020-0820-9

[12] Ji, J.S. (2020) Origins of MERS-CoV, and Lessons for 2019-nCoV. The Lancet, 4, e93. https://doi.org/10.1016/S2542-5196(20)30032-2 
[13] Marcotte, H. and Hammarström, L. (2015) Passive Immunization: Toward Magic Bullets. In: Mestecky, J., Strober, W., Russell, M., Cheroutre, H., Lambrecht, N.B. and Kelsall, B., Eds., Mucosal Immunology, 4th Edition, Elsevier Science, Amsterdam, Chapter 71, 1403-1433.

[14] Cai, H.H. (2018) Therapeutic Monoclonal Antibodies Approved by FDA in 2017. MOJ Immunology, 6, 82-84. https://doi.org/10.15406/moji.2018.06.00198

[15] Özen, M., Gündüz, M. and Haider, H.Kh. (2020) Chimeric Antigen Receptor (CAR) T-Cells as a Therapeutic Modality. In: Haider, H.Kh., Ed., Stem Cells. From Hype to Hope, WSP Company, Singapore, Chapter 8, 211-236. https://doi.org/10.1142/9789811205538_0008

[16] Law, P.L. (2020) System Engineering of Emergent Serum Therapy to Combat COVID-19 and Other Pathogenic Pandemics. OJRM, 9, 8-14.

https://doi.org/10.4236/ojrm.2020.91002

\section{Abbreviations and Acronyms}

2019-nCoV= 2019 novel Coronavirus

Chloroquine $=\mathrm{CQ}$

COVID-19= Coronavirus disease- 19

Hydroxychloroquine $=\mathrm{HQ}$

Middle East Respiratory Syndrome (MERS)-CoV

MAbs $=$ Monoclonal antibodies

Severe Acute Respiratory Syndrome (SARS)-CoV 